\title{
SOL-GEL CHEMISTRY BY RING-OPENING POLYMERIZATION
}

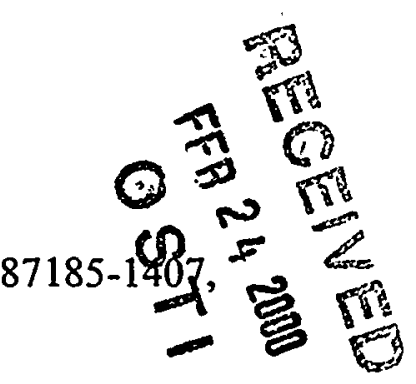

\section{ABSTRACT}

Sol-gel processing of materials is plagued by shrinkage during polymerization of the alkoxide monomers and processing (aging and drying) of the resulting gels. We have developed a new class of hybrid organic-inorganic materials based on the solventless ring-opening polymerization (ROP) of monomers bearing the 2,2,5,5-tetramethyl-2,5disilaoxacyclopentyl group, which permits us to drastically reduce shrinkage in sol-gel processed materials. Because the monomers are polymerized through a chain growth mechanism catalyzed by base rather than the step growth mechanism normally used in sol-gel systems, hydrolysis and condensation products are entirely eliminated. Furthermore, since water is not required for hydrolysis, an alcohol solvent is not necessary. Monomers with two disilaoxacyclopentyl groups, separated by a rigid phenylene group or a more flexible alkylene group, were prepared through disilylation of the corresponding diacetylenes, followed by ring closure and hydrogenation. Anionic polymerization of these materials, either neat or with 2,2,5,5-tetramethyl-2,5-disila-1oxacyclopentane as a copolymer, affords thermally stable transparent gels with no visible shrinkage. These materials provide an easy route to the introduction of sol-gel type materials in encapsulation of microelectronics, which we have successfully demonstrated.

\section{INTRODUCTION}

Hydrolysis and condensation of alkoxysilanes to form highly crosslinked siloxane gels has become synonymous with sol-gel polymerization. ${ }^{[1,2]}$ However, application of these sol-gel systems has been limited by shrinkage associated with evaporation of the solvent needed for monomer/water miscibility and the resulting condensation products formed during polymerization. An attractive strategy for reducing shrinkage is to eliminate solvent ${ }^{[\mathrm{B}}$ and condensation byproducts entirely by replacing the step growth polymerization used in sol-gel processing of alkoxysilanes with a chain growth polymerization, such as ring-opening polymerization (ROP). ROP has proven to be an effective means for reducing or, as with the polymerization of spiroorthocarbonates, completely eliminating shrinkage in linear, hydrocarbon polymers. ${ }^{[4]}$ Here, we report on the ring-opening polymerization of phenylene-bridged disilaoxacyclopentane, 1 , (scheme 1), as well as its copolymerization with the simple 2,2,5,5-tetramethyl-2,5-disila-1oxacyclopentane (4), to make sol-gel type materials and their application in encapsulation of microelectronics. 


\section{DISCLAIMER}

This report was prepared as an account of work sponsored by an agency of the United States Government. Neither the United States Government nor any agency thereof, nor any of their employees, make any warranty, express or implied, or assumes any legal liability or responsibility for the accuracy, completeness, or usefulness of any information, apparatus, product, or process disclosed, or represents that its use would not infringe privately owned rights. Reference herein to any specific commercial product, process, or service by trade name, trademark, manufacturer, or otherwise does not necessarily constitute or imply its endorsement, recommendation, or favoring by the United States Government or any agency thereof. The views and opinions of authors expressed herein do not necessarily state or reflect those of the United States Government or any agency thereof. 


\section{DISCLAIMER}

Portions of this document may be illegible in electronic image products. Images are produced from the best available original document. 

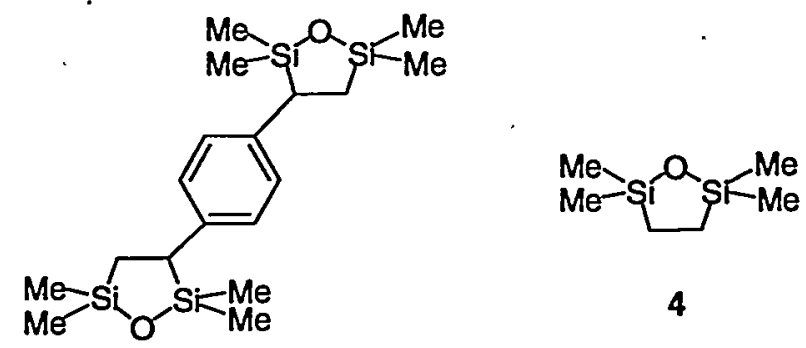

4

1

\section{Scheme 1}
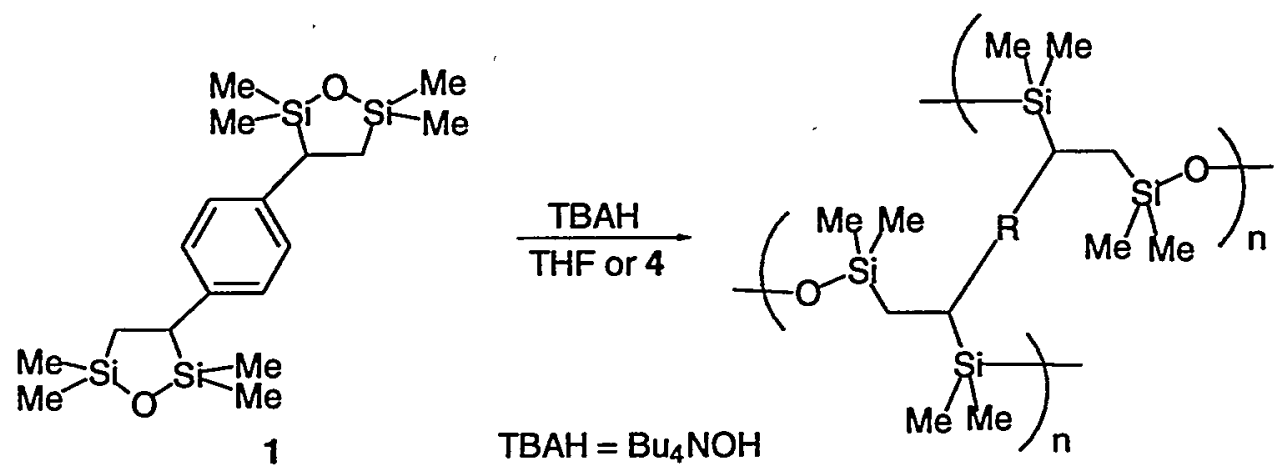

\section{EXPERIMENTAL}

Monomer syntheies. Scheme 2 shows the synthetic scheme for preparation of phenylenebridged disilaoxacyclopentane, 1. All compounds have been fully characterized and experimental details have been published elsewhere. ${ }^{[5]}$

Polymer syntheses. Polymerization of 1 can be achieved either neat as a melt polymerization using octadecylamine as catalyst, or as a solution in THF (1M) using $\mathrm{Bu} \mathrm{u}_{4} \mathrm{NOH}$ (TBAH) as catalyst. Rapid polymerization of all monomers can be achieved when polymerized as a copolymer system with 4 , using TBAH as catalyst.

Scheme 2. Synthetic scheme for monomer 1.<smiles>C#Cc1ccc(C#C)cc1</smiles><smiles>CO[Si](C)(C)/C=C(/C=C([Si](C)(C)OC)[Si](C)(C)OC)[Si](C)(C)OC</smiles><smiles>C[Si]1(C)C=C(c2ccc(C3=C[Si](C)(C)O[Si]3(C)C)cc2)[Si](C)(C)O1</smiles><smiles>C[Si]1(C)CC(c2ccc(C3C[Si](C)(C)O[Si]3(C)C)cc2)[Si](C)(C)O1</smiles> 


\section{RESULTS AND DISCUSSION}

Monomer 1 can readily be polymerized in THF or when dissolved in monomer 4 (used as a solvent/co-monomer) to give transparent, yellow-tinted gels (scheme 1). Furthermore, because the copolymer of 1 and 4 is prepared without solvent, total shrinkage is kept to less than $5 \%$ compared with $50-90 \%$ for traditional sol-gels. Since the resulting gels are insoluble, solid state NMR and infrared spectroscopy are used in their characterization. ${ }^{29} \mathrm{Si}$ NMR confirmed the opening of the disilaoxacyclopentane rings with the pronounced upfield shift in the two observed resonances; 21.9 and 20.9 ppm for 1 in solution and 9.8 and $5.5 \mathrm{ppm}$ for the homopolymer in the solid state. This upfield shift is consistent with the release of ring strain in the five membered ring with ROP. ${ }^{[6]}$ The small peak at $22 \mathrm{ppm}$, in the solid state ${ }^{29} \mathrm{Si}$ NMR spectrum, is attributed to the residual amounts of unreacted pendant disilaoxacyclopentane groups. Ring opening is further confirmed when comparing the IR spectra of 1 and its homopolymer; the resonance at $920.7 \mathrm{~cm}^{-1}$ due to the cyclic SiOSi stretch in 1 is replaced by the broad resonance at $1061.8 \mathrm{~cm}^{-1}$ due to acyclic SiOSi stretches in the homopolymer.
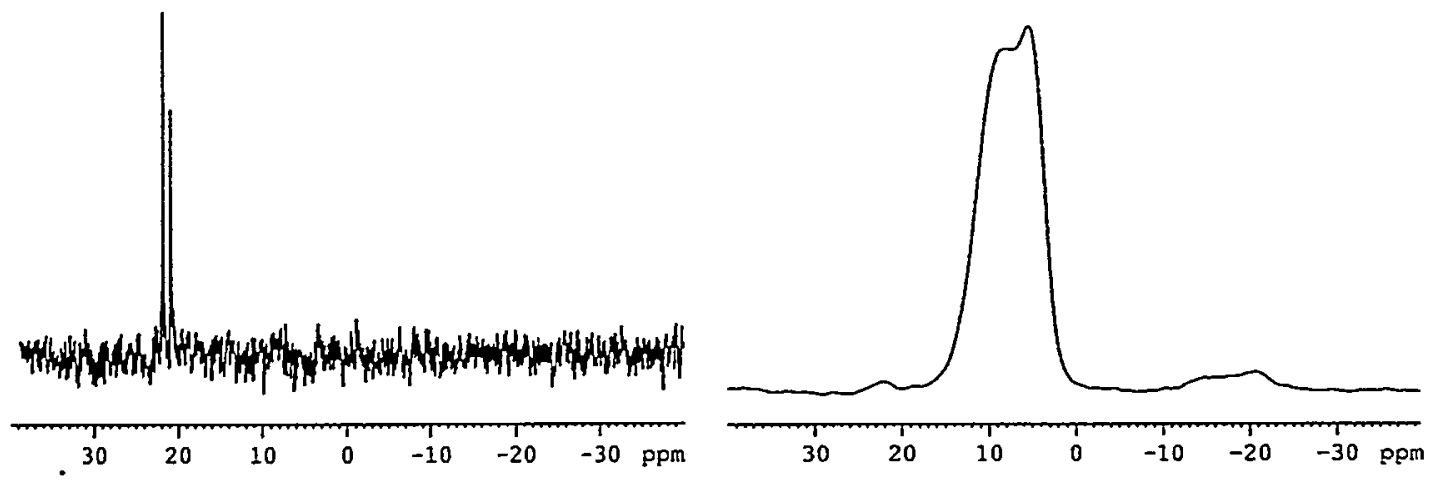

Figure 1. ${ }^{29} \mathrm{Si} \mathrm{NMR}$ spectra for monomer 1 and its homopolymer. NMR resonances for 1 (left spectrum) are 21.9 and $20.9 \mathrm{ppm}$ and those for the polymer (right spectrum) are 9.8 and $5.5 \mathrm{ppm}$.

Exothermic copolymerization of a mixture of 4 and 1 ( $80: 20$ by weight) with TBAH ( $0.17 \mathrm{~mol} \%$ based on dislaoxacyclopentane groups) gives rise to a transparent, crack-free gel within seconds of mixing. Higher catalyst concentration $(0.83 \mathrm{~mol} \%$ based on disilaoxacyclopentanes) leads to generation of enough heat during polymerization to cause a few small bubbles to form (presumably due to monomer volatilization) and become entrapped within the resulting gel. Solid state ${ }^{13} \mathrm{C}$ and ${ }^{29} \mathrm{Si}$ NMR reveal a polymer composition representative of starting co-monomer ratio (80:20) and no detectable unreacted monomer in the final gel.

Thermal gravimetric analysis of the polymers (figure 3 ) revealed robust materials in homopolymer of 1 and its copolymer with 4 compared to the linear polymer of 4 . Homopolymer of 4 begins to degrade at $250^{\circ} \mathrm{C}$ and is completely depolymerized by 500 ${ }^{\circ} \mathrm{C}$. In contrast, the homopolymer of 1 begins to decompose at $375^{\circ} \mathrm{C}$ and leaves a ceramic residue $(17.1 \%)$. Its copolymer with 4 (80:20 ratio shown) displays an initial weight loss of about $4 \%$ followed by complete degradation starting at $500{ }^{\circ} \mathrm{C}$. The 
addition of the phenylene-bridged crosslinker to the polymer of 4 increases the thermal stability by over $150^{\circ} \mathrm{C}$.

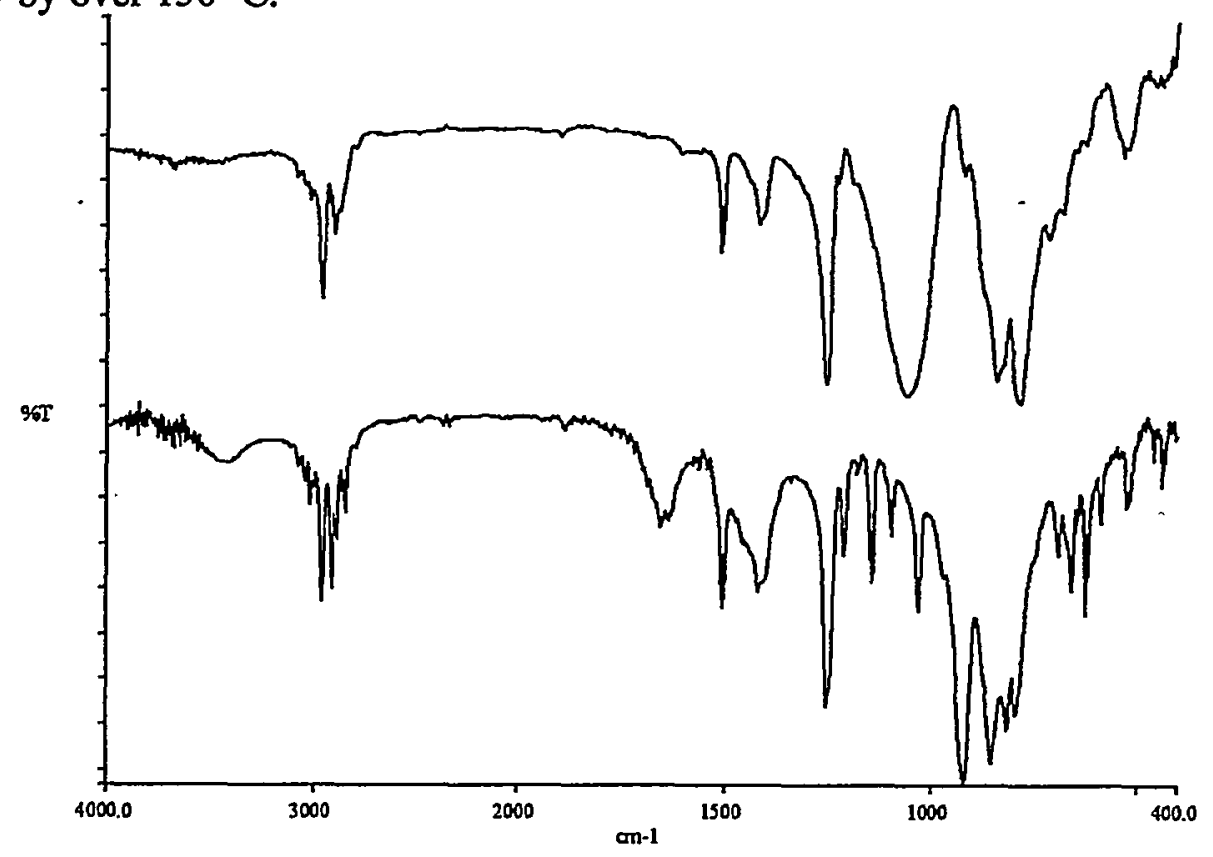

Figure 2. IR spectra of monomer 1 (bottom spectrum) and its homopolymer (top spectrum).

Nitrogen sorption porosimetry and scanning electron microscopy of the homopolymer of 1 , prepared in THF, and the copolymer of 1 and 4 revealed no significant micro- or mesoporosity (figure 4). This lack of porosity suggests that the gels are composed of network polymers that are compliant enough to permit collapse of the pores. ${ }^{[7]}$

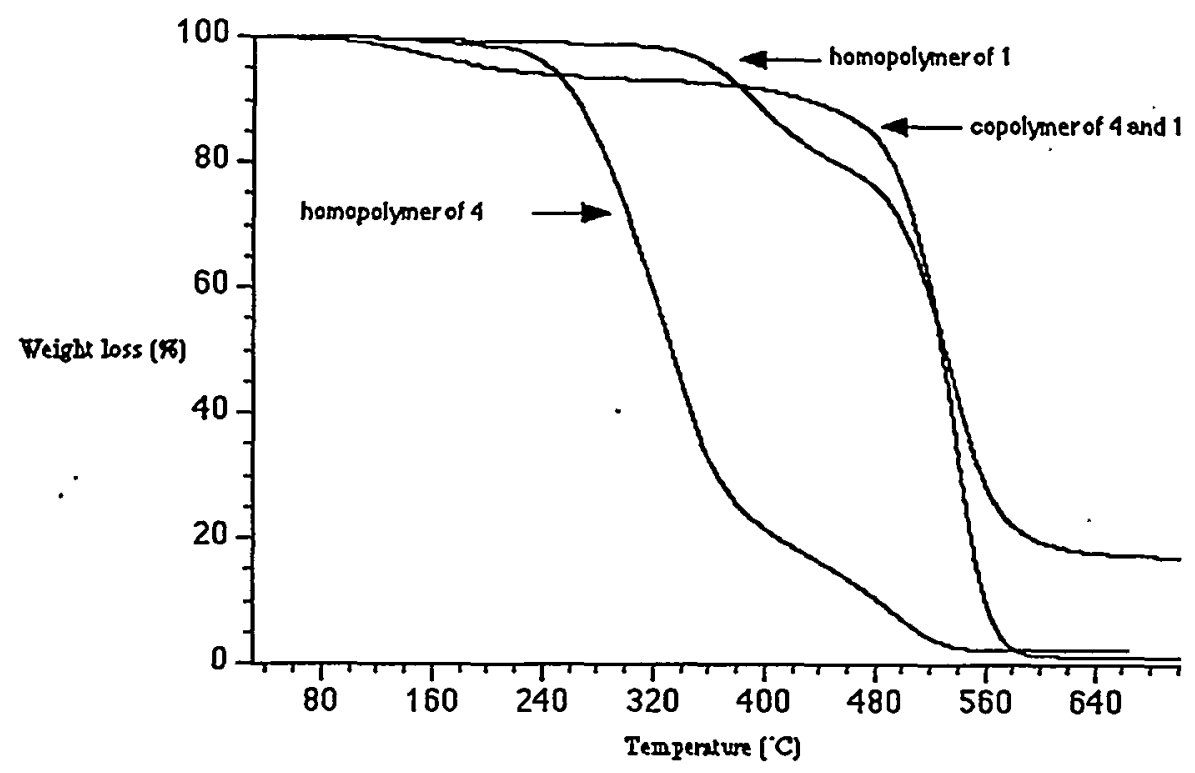

Figure 3. TGA plot comparing the weight loss of homopolymers of 1,4 , and $80: 20$ copolymer of 4 and 1. 

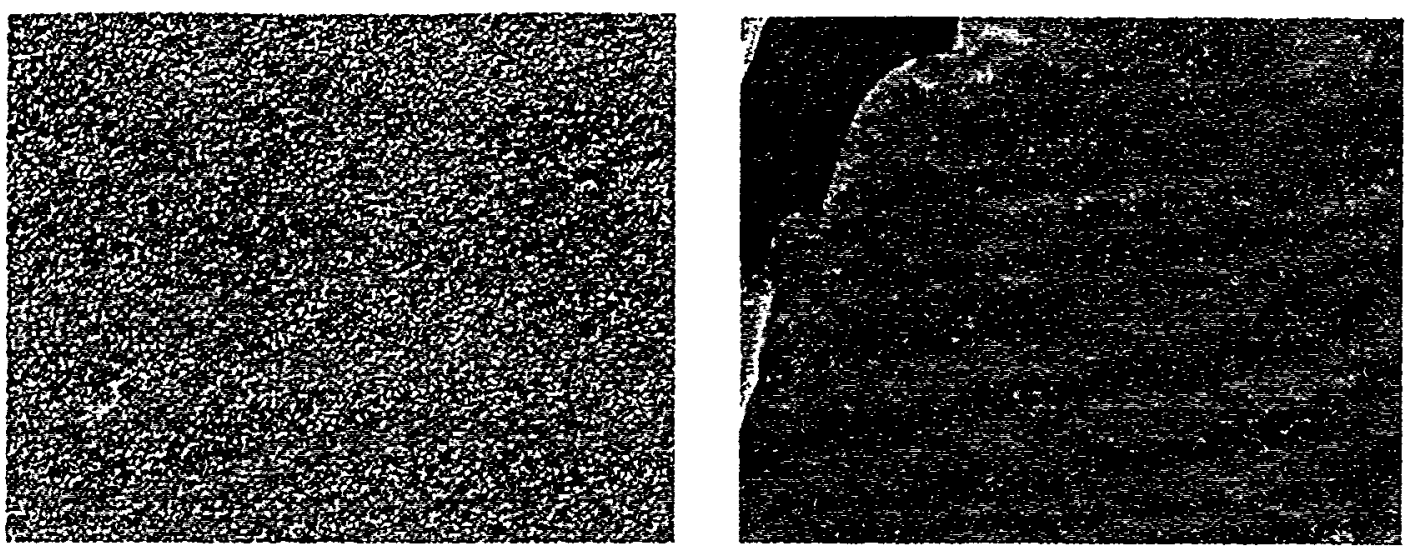

Figure 4. SEM photographs of homopolymer of 1 (left) and 80:20 copolymer of 4 and 1 (right).

A microelectronic test chip was successfully encapsulated using the ROP of the 80/20 mixture of $\mathbf{4}$ and $\mathbf{1}$. The copolymer formed quickly around the test chip as a transparent, slightly yellow resin (figure 5). No visible cracks or shrinkage of the encapsulant were observed.
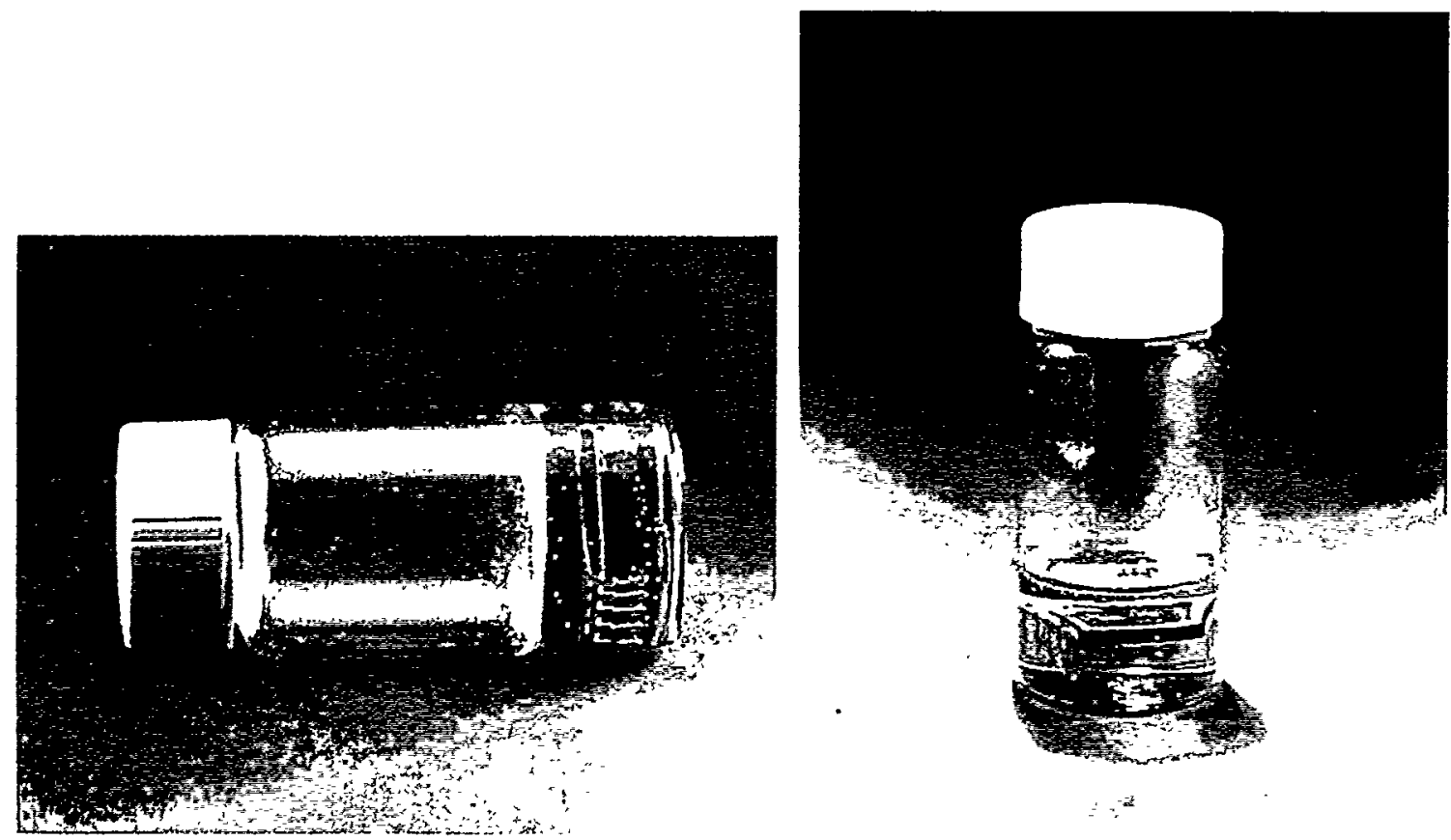

Figure 5. Test microchip encapsulated with copolymer of 4 and 1 (80:20 ratio).

\section{CONCLUSIONS}

We have designed a new class of cyclic siloxane compounds that behave as sol-gel systems when ring-open polymerized using a hydroxide base. These monomers polymerize through chain growth polymerization, unlike conventional alkoxysilane solgel precursors, to form sol-gel polymers. They do not require solvent or water for 
polymerization, show no visible shrinkage or cracking during polymerization and are thermally stable. We have successfully utilized these materials in encapsulation of microelectronics. Current efforts are focused toward expanding this family of ROP monomers and optimization of their mechanical properties.

\section{Acknowledgments}

We would like to thank Duane Schneider and Brigitta Baugher for their unwavering technical support. We would also like to thank Dr. David R. Wheeler and Dr. Gregory M. Jamison for numerous technical discussions relating to this work, and Roger A. Assink and Todd M. Alam for NMR spectroscopy assistance. Sandia is a multiprogram laboratory operated by Sandia Corporation, a Lockheed Martin Company, for the United States Department of Energy under Contract DE-AC04-94AL85000.

\section{References}

[1] C. J. Brinker, G. W. Scherer, Sol-Gel Science: The Physics and Chemistry of Sol-Gel Processing, Academic Press, Inc.: San Diego, 1996.

[2] D. A. Loy, K. J. Shea, Chem. Rev. 1995, 95, 1431.

[3] M. W. Ellsworh, B. M. Novak, Chem. Mater. 1993, 5, 839.

[4] R. K. Sadhir, R. M. Luck, Expanding Monomers: Synthesis, Characterization, and Applications, CRC Press, 1992.

[5] D. A. Loy, K. Rahimian, M. Samara, Angew. Chem. Int. Ed., 1999, 38, 555.

[6] D. Seyferth, J. Robison, Macromolecules, 1993, 26, 407.

[7] J. H. Small, K. J. Shea, D. A. Loy, J. Non-cryst. Solids, 1993, 1. 